\title{
Anakinra as rescue therapy to treat patients with severe COVID-19 refractory to tocilizumab
}

Jaume Alijotas-Reig ( $\nabla$ jalijotas@vhebron.net)

Vall d'Hebron University Hosppital https://orcid.org/0000-0002-9212-3619

\section{Enrique Esteve-Valverde}

Althaia Healthcare University Network of Manresa

\section{Domingo Ruiz-Hidalgo}

Althaia Healthcare University Network of Manresa

\section{Gabriel Lopez-Sanchez}

Althaia Healthcare University Network of Manresa

\section{Ferran Martinez-Valle}

Vall d'Hebron University Hospital

Jaume Trape-Pujol

Althaia Healthcare University Network of Manresa

Francesc Miro-Mur

Vall Hebron Institut de Recerca

\section{Research Article}

Keywords: Anakinra, corticosteroids, COVID-19, Hiperinflammation, Interleukin-1, Interleukin-6, SARS-CoV2, Tocilizumab

Posted Date: October 30th, 2020

DOl: https://doi.org/10.21203/rs.3.rs-100001/v1

License: (c) (1) This work is licensed under a Creative Commons Attribution 4.0 International License. Read Full License

Version of Record: A version of this preprint was published at Archives of Clinical and Biomedical Research on January 1st, 2021. See the published version at https://doi.org/10.26502/acbr.50170215. 
TITLE: Anakinra as rescue therapy to treat patients with severe COVID-19 refractory to tocilizumab. Subtitle: Anakinra for treating refractory severe COVID-19

Authors: Jaume Alijotas-Reig MD, PhD*§, Enrique Esteve-Valverde, MD, PhD§, Domingo Ruiz-Hidalgo MD, PhD, Gabriel López-Sánchez MD, Ferrán Martinez-Valle MD, PhD, Jaume Trapé-Pujol PhD, Francesc Miró-Mur, PhD.

$\S:$ Both authors contributed equally in the manuscript

J. Alijotas-Reig MD, PhD. Senior consultant. Systemic Autoimmune Diseases Unit. Department of Internal Medicine-1. Vall d'Hebron University Hospital. Barcelona. Head, Systemic Autoimmune Research Unit. Vall d'Hebron Research Institute. Professor of Medicine. Department of Medicine. Universitat Autònoma de Barcelona. Barcelona. Spain.

E. Esteve-Valverde MD, PhD. Staff. Department of Internal Medicine. Althaia Healthcare University Network of Manresa. Manresa. Barcelona. Spain.

D. Ruiz-Hidalgo MD, PhD. Head, Department of Internal Medicine. Althaia Healthcare University Network of Manresa. Manresa. Barcelona. Spain. Universitat Central de Catalunya. Barcelona. Spain.

G. López-Sánchez, MD, Staff. Department of Internal Medicine.Althaia Healthcare University Network of Manresa. Manresa. Barcelona. Spain.

F. Martínez-Valle, MD, PhD. Systemic Autoimmune Diseases Unit. Department of Internal Medicine-1. Vall d'Hebron University Hospital. Barcelona. Universitat Autònoma de Barcelona. Barcelona. Spain.

Jaume Trapé-Pujol PhD. Head, Laboratory Department. Althaia Healthcare University Network of Manresa. Manresa. Barcelona. Spain.

F. Miró-Mur. PhD. Senior research. Systemic Autoimmune Research Unit. Vall d'Hebron Research Institute. Barcelona. Spain.

\section{*Corresponding author:}

Jaume Alijotas-Reig M.D, PhD, MSc.

Systemic Autoimmune Diseases Unit. Department of Internal Medicine-1. Vall d'Hebron University Hospital. Passeig Vall d'Hebron 119-129. 08035 Barcelona. Spain.

Phone: +34 93489 4194; Fax: +34 934893039 e-mail: jalijotas@vhebron.net 


\section{Disclosure of Interest}

The authors stated that they do not have any commercial or any other type of interest that may have influenced the drawing up and the results of this paper.

Word count: 2350

Tables: 2

Figure: 1 


\section{ABSTRACT}

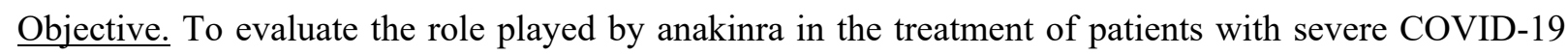
who fail to "accepted" standard of care and tocilizumab.

Methods. We conducted a retrospective cohort study assessed in Althaia Health Network University and Vall d'Hebrón University Hospital, in Barcelona, Spain. We included patients with confirmed RT-PCR for SARS-CoV-2, moderate-to-severe acute respiratory distress syndrome [PaO2:FiO2] (PAFI) $\leq 200$ $\mathrm{mmHg}$, and hyperinflammation. All of them were primarily managed with non-invasive ventilation outside of the ICU and received standard of care with hydroxychloroquine, lopinavir/ritonavir, azithromycin, and enoxaparin supplemented with tocilizumab. These patients received an additional administration of $100 \mathrm{mg}$ subcutaneous anakinra twice a day (low-dose) or every 6-8 hours (mediumdose). Mechanical ventilation-free survival, ICU admission, respiratory function changes (PAFI), inflammatory markers, and survival were analyzed.

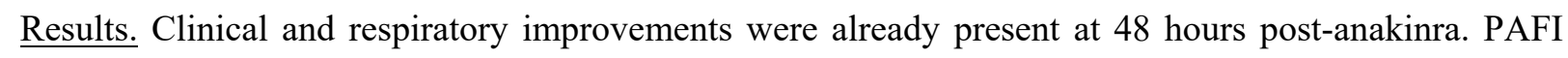
increased $105.2 \%$ at 48 hours over anakinra administration and $166.9 \%$ at day 7 . Respiratory function improvement was significant at day $7(\mathrm{p}<0.0001)$ with $10 / 12(83 \%)$ responders having a PAFI $\geq 200$ $\mathrm{mm} \mathrm{Hg}$. Despite of this improvement, inflammatory markers lasted to decrease. Two patients required ICU and temporary mechanical ventilation. No patients died and no adverse effects related to anakinra appeared. Short-time follow-up showed no relapses.

Conclusions. In severe ARDS related to SARS-CoV-2 refractory to standard of care plus tocilizumab, low-to-moderate doses of anakinra as a rescue therapy showed effectiveness and safety, avoiding mechanical ventilation and deaths. 


\section{INTRODUCTION}

Severe acute respiratory syndrome related to Coronavirus-2 (SARS-CoV-2) infection causes the coronavirus disease 2019 (COVID-19). Clinical manifestations range from asymptomatic or mild forms, through flu syndrome to systemic inflammatory response with acute respiratory distress syndrome (ARDS). In areas where the COVID-19 pandemic is overwhelming, the number of patients with severe COVID-19 and ARDS has exceeded long the capacity of intensive care units (ICU). Since the declaration of a pandemic by the World Health Organization (WHO) in March 2020, clinicians have started a race to find an effective treatment to prevent and cure the development of the most serious forms of the disease. Current management of COVID-19 is supportive, and respiratory failure from ARDS is the main cause of death [1,2]. Mortality in patients with COVID-19 and ARDS who are admitted to the intensive care unit (ICU) is high, ranging from $26 \%$ to $78 \%$ [1-3]. Interestingly, mortality is increased in patients with pronounced systemic/ pulmonary inflammation and symptoms driven by IL-1 are the most common in COVID-19 patients. The current pharmacologic empiric management of these severe forms included biologic drugs, among them, interleukin (IL)-1 and IL-6 blockers [4,5]. In the current practice, IL-6 blocker tocilizumab (TCZ) is primarily used in addition with the "accepted" standard of care that includes: antiviral plus hydroxychloroquine plus prophylactic LMWH and sometimes methylprednisolone/dexamethasone [6] Other immunosuppressives are also empirically been used, such as, intravenous immunoglobulins (IVIG), cyclosporine A (CyA), JAK/STAT inhibitors or plasma hiperimmune [4]. Even so, some patients fail to this schema leading them to mechanical ventilation and eventually to death.

Anakinra is an interleukin IL-1 receptor antagonist that blocks activity of the proinflammatory cytokines IL-1 $\alpha$ and IL-1 $\beta$ and is used to treat autoinflammatory/rheumatic disorders at a daily dose of $100 \mathrm{mg}$ subcutaneously [7]. Interestingly, a subgroup of patients with COVID-19 shows hyperinflammatory syndrome that resemble the cytokine storm related to macrophage activation syndrome, with release of IL-1, IL-6, IL-18, and interferon $\gamma[3,4]$. Cytokine blocking agents, including high-dose anakinra, are effective treatments for these disorders [8]. Preliminary series of patients with severe COVID-19 treated with low-to-high dose anakinra have yielded promising results [8-12]. In addition, anakinra has a remarkable safety when compared with other IL blockers particularly because of its short half-life, which allows prompt discontinuation, minimizing the risk of infection being, therefore, suitable for use 
in critically ill patients [5]. We aimed to assess clinical response at 48 hours, at 7 days and outcomes at discharge in 12 consecutive patients with severe COVID-19, ARDS, and hyperinflammatory syndrome outside the ICU who received anakinra in addition to non-invasive ventilation and who had been nonresponders or refractory to standard of care plus tocilizumab.

\section{MATERIAL AND METHODS}

\subsection{Patients and study design}

From mid-March until end of May, patients with severe COVID-19 who required in-hospital management and that were "refractory" or who failed to standard of care plus TCZ, were retrospectively assessed in two university tertiary hospitals, Althaia Network and Vall d'Hebron University Hospital, both in Barcelona, Spain. COVID-19 was diagnosed by quantitative RT-PCR and either chest radiography or CT. Moderate to severe ARDS-related to SARS-CoV-2 was defined as acute-onset respiratory failure with bilateral infiltrates on chest radiography or CT, hypoxemia (ratio of the partial pressure of oxygen in arterial blood to the fractional concentration of oxygen in inspired air [PaO2:FiO2] $\leq 200 \mathrm{~mm} \mathrm{Hg}$ with a positive end-expiratory pressure [PEEP] of at least $5 \mathrm{~cm} \mathrm{H2O}$ ), and no evidence of left atrial hypertension. Hyperinflammatory syndrome was defined as ferritin $\geq 800 \mathrm{ng} / \mathrm{ml}$ or C-reactive protein $(\mathrm{CRP}) \geq 100 \mathrm{mg} / \mathrm{L}$ or $\mathrm{D}$-dimer $\geq 1000 \mu \mathrm{g} / \mathrm{L}$ or $\mathrm{IL}-6 \geq 40 \mathrm{pg} / \mathrm{ml}$ or some of them. At that time, the accepted "standard of care" included: azithromycin plus hydroxychloroquine plus lopinavir/ ritonavir plus prophylactic low-molecular weight heparin and low-to-moderate-dose methylprednisolone for three days.

When clinical, laboratory tests and mainly respiratory function data did not improve or worsen, patients were put on TCZ $600 \mathrm{mg}$ intravenous (iv) in single or double doses 12 hours apart. Patient number 1 was also put on IVIG and patient 5 on remdesivir for 5 days. If patients showed no improvement in the ventilatory values, a rescue therapy with anakinra (Kineret ${ }^{\circledR}$, Swedish Orphan Biovitrum, Stockholm, Sweden) was started.

Patients younger than 18 years-old, those that were already admitted to the ICU for mechanical ventilation, with evidence of bacterial infection before anakinra use, individuals with concomitant administration of other cytokine blockers or JAK-inhibitors or hyperimmune plasma, and people who had been enrolled concomitantly in clinical trials were excluded. Time of response, mechanical 
ventilation-free survival, survival, changes in ferritin, D-dimer, C-reactive protein, lymphocyte count and clinical status in this cohort was registered at 24 hours (not depicted), 48 hours, 7 days after anakinra treatment. Clinical status, pulmonary function at discharge, re-admissions and mortality were also evaluated.

\subsection{Treatment with anakinra}

Anakinra $100 \mathrm{mg}$ twice subcutaneously during three days followed by $100 \mathrm{mg}$ once a day during 4 days, was added (compassionate use). Two cases (number 11 and 12) received 3-day course of $100 \mathrm{mg}$ q6 hours with further reduction doses. Treatment was maintained empirically 7 days until achieve sustained clinical benefit, defined as a reduction of inflammatory markers and, particularly, sustained respiratory improvement $(\mathrm{PaO} 2: \mathrm{FiO} 2>200 \mathrm{~mm} \mathrm{Hg})$ for at least 2 days. In patients achieving sustained clinical benefit, discontinuation of anakinra was followed empirically by decreasing dose each three days until cessation which was deemed useful to avoid possible inflammatory relapses. Lack of clinical improvement at 7 days, the apparition of bacteremia/sepsis or side-effects (e.g, increase in liver aminotransferase enzymes above three-four fold the upper normal limit) were considered causes to cease anakinra treatment.

\section{$\underline{2.3 \text { Main outcomes }}$}

The primary outcome was to evaluate the clinical response, particularly the pulmonary function and the mortality rate. Arbitrarily, we defined PAFI $\geq 200 \mathrm{mmHg}$ at day 7 post anakinra as marker of response. Secondly, to evaluate the number of cases that needed MV and ICU admissions.

Owing to their clinical status and the emergency of the situation, patients were orally informed and all of them gave their consent orally. This information was reordered in an electronic medical history.

\subsection{Ethics}

This study has been carried out in accordance with The Code of Ethics of the World Medical Association (Declaration of Helsinki) for experiments involving humans. In addition, ethical approval for this study - Project No PR(AG)204/2020 - was provided by the Ethical Committee of Vall d'Hebron University Hospital, Barcelona, Spain (Chaiperson: Soledad Gallego-Melcón) met in regular session No. 445 on March $26^{\text {th }}, 2020$.

\subsection{Statistics}


Data were analyzed with GraphPad Prism version 6 (San Diego, Cal, USA) and statistics performed with the embedded software. Comparisons among treatment progression were done with non-parametric one-way ANOVA (Dunn's multiple comparisons).

\section{RESULTS}

From mid-March until end of May, 15 patients received subcutaneous (sc) anakinra after standard treatment plus tocilizumab and plus non-invasive ventilation failed. Three out of 15 cases were excluded because they only received anakinra for 1 or 2 days. Finally, 12 cases were included for analyses. Main epidemiological data, clinical and analytical results at patient admission are depicted in Table 1. Briefly, the mean age was 60 (range: 20-80), with male predominance (8/4). At admission, all showed tachypnea and PAFI were abnormal in 8/12 (66.67\%) cases. Ferritin, CRP, LDH, D-dimer and IL-6 levels were elevated in all cases. All but three (75\%) showed absolute and marked lymphocytopenia. (see Table 1). Main clinical and analytical findings after TCZ and anakinra administration are shown in Tables 1 and 2. Before anakinra, fifty percent of cases had PAFI $\leq 100 \mathrm{~mm} \mathrm{Hg}$ ant the remainder $\leq 150 \mathrm{~mm} \mathrm{Hg}$. Interestingly, clinical and respiratory improvement began at 48 hours post anakinra in 10/12 (83\%) cases. In the responders at 48-hours, PAFI increases a mean of $133.80 \mathrm{~mm} \mathrm{Hg}$ (range: 28-239) and in percentage a mean of $132.01 \%$ (range: $23.33-356.72$ ). While considering all patients, PAFI percentage increased $105.18 \%$ (range: $-50.00-356.72$ ). The two non-responders (patients number 1 and 6 ) were also discharged after long-hospital stay. Infectious complications appeared in patient 1 with bacteriuria and bacteremia. At 48 hours post anakinra, CRP, D-dimer, ferritin levels and lymphocyte count improved only in $30-40 \%$ of cases. At day 7 post anakinra, clinical status and PAFI showed improvement in all patients but 10/12 (83\%) accomplished the criteria of respiratory improvement (PAFI $\geq 200 \mathrm{~mm} \mathrm{Hg}$; Table 1 bottom panel; Figure 1A). Overall, at this time a significant increase of PAFI $[288.6 \pm 58.14$ $\mathrm{mm} \mathrm{Hg}($ mean $\pm \mathrm{SD}), \mathrm{p}<0.0001]$ was observed over PAFI at anakinra administration $[124.5 \pm 44.42 \mathrm{~mm}$ $\mathrm{Hg}$ ] (Figure 1B). At discharge, improvement or normalization of inflammatory parameters and respiratory function were attained in all treated cases (12/12). Patient 1 and 6 were considered as anakinra non-responders because PAFI were $<200 \mathrm{mmHg}$ at day 7. Patients number 1 and 7 needed mechanical ventilation (MV). The latter case was put on MV but could be extubated at day 3 post anakinra. The reminder patients did not require MV. No deaths occurred in this series (Table 2). Patients 
remained in the hospital for an average of 20,8 days (range: 14-35) and were finally discharged with subsequent follow-up in outpatient clinic. After 4-8 weeks, no patients needed to be readmitted.

\section{DISCUSION}

In this retrospective case-series of 12 patients with poor response to accepted standard of care plus TCZ for severe COVID-19, a 7-day course of low-to-moderate subcutaneous anakinra showed already clinical benefit at 48 hours in 10 of 12 cases with maintenance at 7 days and untill discharge. This fact allowed us to avoid intubation in all but one responders. Treatment was well tolerated, and discontinuation was not followed by clinical relapses. Our study is the first to report benefits in nonintubated patients with severe COVID-19 and ARDS treated with anakinra who previously failed to IL6 blockade with TCZ treatment.

Since the coronavirus pandemic began, the scientific community encountered many difficulties to protocolize the use of antiviral and immunomodulatory-anti-inflammatory treatments that slow-down the inflammatory cascade and the evolution towards severe respiratory distress. In severe and lifethreatening COVID-19 forms, activation of inflammasome NLRP3 participates in the release of high amounts of pro-inflammatory cytokines, particularly IL-1 and IL-18. In addition, the activation of NFkB pathway favors the release of IL- 6 and IL- $8[4,8]$. Thus, it appears to be a rationale for using IL-1 and/or IL-6 blockers in the therapeutics of COVID-19. The IL-6 blocker TCZ administered with the same protocol used in cytokine release syndrome secondary to chimeric antigen receptor-T therapies has provided encouraging preliminary results [13]. However, cases with TCZ failure do exist, prompting the search for alternative therapeutic strategies based on other cytokine blockers. In addition, since IL-1 can induce IL-6 release, it is possible that anakinra could be more effective blocking the cytokine storm. Anakinra $\left(\right.$ Kineret $\left.{ }^{\circledR}\right)$ is a recombinant, non-glycosylated form of the human interleukin-1 receptor antagonist (IL-1Ra). It is produced by recombinant DNA technology. The possibility to be administered sc or iv route is an advantage, although the $95 \%$ bioavailability after a single sc bolus administration makes unnecessary the iv route [5,14]. Data on the doses able to block IL- $1 \alpha$ and IL-1 $\beta$ in severe COVID-19 cases are unknown yet. Off-label doses of anakinra either $100 \mathrm{mg}$ twice daily sc or up to 10 $\mathrm{mg} / \mathrm{kg} /$ day iv have been used [9-12]. To our knowledge, there are no published studies comparing diverse anakinra doses in the COVID-19. The length of anakinra treatment is also empirical. A time- 
course of 7 to 10 days has been the most used for the few published studies [9-12]. Noteworthy, in our series, only two patients were admitted in ICU and invasive ventilation was temporary needed. Importantly, there were no deaths. Although this series was not including controls, the published expected mortality in similar cases not treated with anakinra was as high as $27-78 \%$ [1-3]. The accepted clinical risk factors for poor outcomes in severe COVID-19 such as $\geq 65$ years old, hypertension, coronary heart disease or diabetes mellitus (DM) were poorly represented in our series, being only type$2 \mathrm{DM}$ and obesity presented in 1 and 3 cases, respectively. Interestingly, 5 cases (41.6\%) were older than 65. Overt hypertension and heart disease were not disclosed at admission. These facts could explain in part the absence of mortality in these patients. Although all of them were treated with the "standard of care" and TCZ at full dose, they presented a poor evolution till anakinra was administered. Hence, we think anakinra could have played a major role to achieve a good outcome. PAFI has been the better objective marker for severity and for good recovery too. The increase of PAFI at 48 hours post anakinra treatment was present and really notable at day 7 , and was associated with a clinical improvement and decreasing oxygen requirements. Similar results have been found by Cavalli et al [9], Dimopoulos et al [10], Aouba et al [11] and Portoli et al [12]. However, in our study markers of hyperinflammation such as CRP, ferritin, LDH or D-dimer did not diminish in all cases as fast as expected. In these previously mentioned series, the mortality ranged from 0 to $40 \%$ although this latter result happened in cases with hemophagocytic syndrome related to severe COVID-19 [13]. Recently, Navarro-Millán et al [15] reported that sc administration of anakinra was able to avoid MV and reduce mortality in ARDS patients with COVID-19.

In our series, bacterial infection was only present in one case that resolved with antibiotic treatment. Thus, a 7-day course of anakinra did not suppose an added risk factor for bacterial superinfection in these non-intubated patients. The short half-live of anakinra (4 to 6 hours) and relatively short length of treatment may suppose an advantage compared with other biologic drugs such as IL-6 or TNF inhibitors in terms of preventing bacterial infection $[5,15]$.

However, this study has several limitations, particularly a small sample size and the absence of controls. The strong point is the selected cases that include only those patients refractory to corticosteroids and IL-6 blockade.

\section{Conclusion}


In conclusion, in severe ARDS related to SARS-CoV-2 refractory to standard of care plus tocilizumab, low-to-moderate dose of anakinra as a rescue therapy showed effectiveness and safety, avoiding ICU admissions, intubation and mechanical ventilation and deaths. 


\section{ACKNOWLEDGEMENTS}

We thanks Ms. Ariadna Anunciacion-Llunell for helping us in the drafting of the manuscript. 


\section{REFERENCES}

[1]. Grasselli G, et al. Baseline characteristics and outcomes of 1591 patients infected with SARSCoV-2 admitted to ICUs of the Lombardy region, Italy. JAMA; published online April 6 . DOI:10.1001/jama.2020.5394 (2020)

[2.] Huang C, et al. Clinical features of patients infected. with 2019 novel coronavirus in Wuhan, China. Lancet ; 395: 497-506 (2020).

[3]. Zhou F, et al. Clinical course and risk factors for mortality of adult inpatients with COVID-19 in Wuhan, China: a retrospective cohort study. Lancet ; 395: 1054-62 (2020).

[4]. Alijotas-Reig J, et al. Immunomodulatory therapy for the management of severe COVID-19. Beyond the anti-viral therapy: A comprehensive review.. .Autoimmun Rev;19:102569. doi: 10.1016/j.autrev.2020.102569. Epub 2020 May 3 (2020)

[5]. Muñoz-Jiménez A, Rubio-Romero E, Marenco de la Fuente JL. Proposal for the use of anakinra in acute respiratory distress secondary to Covid-19. Reumatol Clin. 2020. https://doi.org/10.1016/j.reuma.2020.04.009. (2020)

[6]. World Health Organization. Clinical management of severe acute respiratory infection (SARI) when COVID-19 disease is suspected Interim guidance 13 March 2020.

[7]. Fleischmann RM, et al. Anakinra, a recombinant human interleukin-1 receptor antagonist (rmetHuIL-1ra), in patients with rheumatoid arthritis: A large, international, multicenter, placebocontrolled trial. Arthritis Rheum. ;48:927-34, (2003).

[8]. Grom AA, Horne A, De Benedetti F. Macrophage activation syndrome in the era of biologic therapy. Nat Rev Rheumatol ;12: 259-68, (2016).

[9]. Cavalli G, et al. Interleukin-1 blockade with high-dose anakinra in patients with COVID-19, acute respiratory distress syndrome, and hyperinflammation: a retrospective cohort study. Lancet Rheumatol ;2: e325-31; doi.org/10.1016/S2665-9913(20)30127-2. (2020)

[10]. Dimopoulos de Mast Q, et al. Favorable Anakinra Responses in Severe Covid-19 Patients with Secondary Hemophagocytic Lymphohistiocytosis, Cell Host \& Microbe , https://doi.org/10.1016/j.chom.2020.05.007. (2020) 
[11]. Aouba A, et al. Targeting the inflammatory cascade with anakinra in moderate to severe COVID19 pneumonia: case series. Ann Rheum Dis 2020;0:1-2. doi:10.1136/annrheumdis-2020-217706. (2020)

[12]. Pontali E, et al. Safety and efficacy of early high-dose IV anakinra in severe COVID-19 lung disease. J Allergy Clin Immunol; doi.org/10.1016/j.jaci.2020.05.002 (2020).

[13]. Suntharalingam G, Perry MR, Ward S, Brett SJ, Castello-Cortes A, Brunner MD, Panoskaltsis N. Cytokine storm in a phase 1 trial of the anti-CD28 monoclonal antibody TGN1412. N Engl J. Med 355: 1018-28. (2006).

[14]. Kineret, INN-Anakinra. European Medicines Agency. Available on: https://www.ema.europa.eu/en/documents/product-information/kineret-epar-product-.pdf. Accessed at: July $6^{\text {th }}, 2020$.

[15]. Navarro-Millan-I, Sattui-Cortes S, Siegel C, Kuntz-Crow M. Use of Anakinra to prevent mechanical ventilation in severe COVID-19: A case series. Arthritis Rheumatol; doi:10.1002/art.41422. (2020). 


\section{AUTHOR'S CONTRIBUTION}

Jaume Alijotas-Reig (JAR) Enrique Esteve-Valverde (EEV) Domingo Ruiz-Hidalgo (DRI) Gabriel LópezSánchez (GLS) Ferrán Martinez-Valle (FMV) Jaume Trapé-Pujol (JTP), Francesc Miró-Mur (FMM)

Conception or design of the work: JAR; EEV; DRI; FMV; FMM

Data acquisition: JAR; EEV; GLS; JTP; FMM

Analysis and interpretation of data for the work: All authors

Drafting the work: JAR; EEV; FMM

Revising the work critically for important intellectual content: All authors

Final approval of the version to be published: All authors

Agreement to the work contents: All authors 


\section{Figure legends}

Figure 1. PAFI evolution during patient hospitalization. (A) Patients from 1 to 12 are showed individually and each bar represent PAFI assessment at a specific time during treatment. (B) Comparisons of PAFI among treatments over time. Each dot represents a patient. Non-parametric one-way ANOVA with Dunn's multiple comparisons (ns, non-significant; ** $\mathrm{p}<0.01$; **** $\mathrm{p}<0.0001$ ). Legend: Adm, admission; TCZ 24h, 24 hours after tocilizumab administration; ANK 0h, at the moment of anakinra administration; ANK 48h, 48 hours after anakinra administration; ANK 7d, 7 days after anakinra administration; Disch, discharge. 
Table 1. Mean epidemiological features. Clinical and analytical results of patients at admission and after tocilizumab and anakinra administration

\begin{tabular}{|c|c|c|c|c|c|c|c|c|c|c|c|c|}
\hline Patient & Sex & Age & Medical History & DDO & $\underset{(\mathbf{m m ~ H g})}{\text { PAFI }}$ & $\underset{\left(\mathbf{m i n}^{-1}\right)}{\mathbf{B R}}$ & $\begin{array}{c}\text { total lymphocytes } \\
(\mu \mathrm{L})\end{array}$ & $\begin{array}{l}\text { D-dimer } \\
\text { (ng/mL) }\end{array}$ & $\begin{array}{l}\text { LDH } \\
(\mathbf{u} / \mathbf{L})\end{array}$ & $\begin{array}{c}\text { Serum Ferritin } \\
(\mu \mathrm{g} / \mathrm{L})\end{array}$ & $\begin{array}{c}\mathrm{CRP} \\
(\mathrm{mg} / \mathrm{L})\end{array}$ & $\begin{array}{c}\text { IL-6 } \\
(\mathrm{pg} / \mathrm{mL})\end{array}$ \\
\hline 1 & M & 74 & DLP. Prostate cancer & 9 & 196 & 34 & 500 & 336 & 664 & 821 & 208.3 & 196.3 \\
\hline 2 & M & 58 & Obesity & 5 & 310 & 30 & 500 & 214 & 800 & 1171 & 80.7 & 42.01 \\
\hline 3 & M & 49 & None & 5 & 300 & 22 & 600 & 343 & 414 & 1126 & 28.2 & 23.31 \\
\hline 4 & $\mathrm{~F}$ & 20 & None & 5 & 310 & 24 & 500 & 290 & 781 & 1260 & 106.6 & 50.59 \\
\hline 5 & $\mathrm{~F}$ & 74 & Obesity & 2 & 242 & 28 & 400 & 184 & 370 & 244 & 58.2 & 26.14 \\
\hline 6 & $\mathrm{~F}$ & 60 & Obesity & 3 & 324 & 30 & 1400 & 174 & 356 & 228 & 23.3 & 10.25 \\
\hline 7 & M & 67 & Smoker. DLP. CKD & 8 & 195 & 30 & 700 & 450 & 1037 & 1992 & 187.6 & 108.7 \\
\hline 8 & $\mathrm{~F}$ & 52 & HBP & 5 & 286 & 22 & 700 & 187 & 707 & 1339 & 83.2 & 36.1 \\
\hline 9 & M & 80 & HBP & 15 & 277 & 20 & 2300 & 4974 & 1300 & 1754 & 14.4 & 17.84 \\
\hline 10 & M & 75 & Smoker. DM2NID & 8 & 229 & 24 & 500 & 320 & 620 & 1234 & 182.5 & 196.6 \\
\hline 11 & M & 46 & Down Syndrome & 5 & 232 & 24 & 1900 & 3181 & 242 & 857 & 7.26 & 32 \\
\hline 12 & M & 65 & HBP. AoI & 14 & 200 & 28 & 400 & 141 & 395 & 980 & 10.8 & 42 \\
\hline
\end{tabular}

\begin{tabular}{|c|c|c|c|c|c|c|c|c|c|c|c|c|c|c|c|c|}
\hline Patient & $\begin{array}{c}\text { DDO } \\
\text { TCZ } \\
\text { admin }\end{array}$ & $\begin{array}{l}\text { D-dimer } \\
24 \text { hours } \\
\text { post TCZ }\end{array}$ & $\begin{array}{l}\text { Ferritin } \\
24 \text { hours } \\
\text { post } T C Z\end{array}$ & $\begin{array}{l}\text { Lympho } \\
24 \text { hours } \\
\text { post TCZ }\end{array}$ & $\begin{array}{c}\text { PAFI } \\
24 \text { hours } \\
\text { post TCZ }\end{array}$ & $\begin{array}{c}\text { DDO } \\
\text { ANK } \\
\text { admin }\end{array}$ & $\begin{array}{c}\text { PAFI } \\
\text { at ANK } \\
\text { admin }\end{array}$ & $\begin{array}{l}\text { D-dimer } \\
\text { at ANK } \\
\text { admin }\end{array}$ & $\begin{array}{c}\text { Ferritin } \\
\text { at ANK } \\
\text { admin }\end{array}$ & $\begin{array}{c}\text { Lympho } \\
\text { at ANK } \\
\text { admin }\end{array}$ & $\begin{array}{c}\text { PAFI } \\
48 \text { hours } \\
\text { post ANK }\end{array}$ & $\begin{array}{l}\text { D-dimer } \\
48 \text { hours } \\
\text { post ANK }\end{array}$ & $\begin{array}{c}\text { Ferritin } \\
48 \text { hours } \\
\text { post ANK }\end{array}$ & $\begin{array}{l}\text { Lympho } \\
48 \text { hours } \\
\text { post ANK }\end{array}$ & $\begin{array}{c}\text { PAFI } \\
7 \text { days } \\
\text { post ANK }\end{array}$ & $\begin{array}{c}\text { PAFI } \\
\text { at patient } \\
\text { discharge }\end{array}$ \\
\hline 1 & 9 & 286 & 810 & 400 & $200^{*}$ & 11 & $150^{*}$ & 576 & 684 & 600 & $75^{*}$ & 398 & 560 & 600 & 188 & 292 \\
\hline 2 & 5 & 217 & 1330 & 1500 & $67^{*}$ & 16 & $67^{*}$ & 678 & 1651 & 800 & 306 & 531 & 1683 & 900 & 358 & 364 \\
\hline 3 & 11 & 352 & 1167 & 600 & 381 & 18 & 180 & 479 & 2004 & 400 & 346 & 616 & 2672 & 700 & 349 & 360 \\
\hline 4 & 7 & 420 & 2773 & 900 & $155^{*}$ & 11 & $94 *$ & 438 & 2399 & 900 & 292 & 1188 & 3754 & 800 & 310 & 358 \\
\hline 5 & 2 & 594 & 743 & 800 & $110^{*}$ & 3 & $120^{*}$ & 594 & 743 & 500 & $148^{*}$ & 530 & 919 & 500 & 282 & 370 \\
\hline 6 & 3 & 149 & 550 & 1600 & 202 & 6 & $153^{*}$ & 338 & 1146 & 800 & $141^{*}$ & 367 & 1455 & 1100 & 174 & 360 \\
\hline 7 & 8 & 426 & 1693 & 600 & 400 & 14 & $84^{*}$ & 426 & 1693 & 600 & $165^{*}$ & 770 & 2320 & 600 & 255 & 355 \\
\hline 8 & 8 & 186 & 2946 & 300 & $112^{*}$ & 9 & $112 *$ & 225 & 980 & 1000 & 253 & $\mathrm{U}$ & $\mathrm{U}$ & $\mathrm{U}$ & 337 & 360 \\
\hline 9 & 15 & 3340 & 1395 & 1300 & 181 & 28 & 190 & 3106 & 1544 & 600 & $324 *$ & 1068 & 1317 & 1000 & 307 & 362 \\
\hline 10 & 9 & 342 & 1284 & 600 & 315 & 12 & $74^{*}$ & 470 & 1335 & 700 & $115^{*}$ & 1926 & 1096 & 800 & 283 & 340 \\
\hline 11 & 16 & 336 & 1318 & 2200 & $108^{*}$ & 18 & $90^{*}$ & 323 & 1156 & 2700 & 300 & $\mathrm{U}$ & 1000 & 1900 & 320 & 320 \\
\hline 12 & 20 & 625 & 444 & 400 & 180 & 23 & 180 & 156 & 943 & 1000 & 280 & 740 & 440 & 800 & 300 & 350 \\
\hline
\end{tabular}

*Optiflow

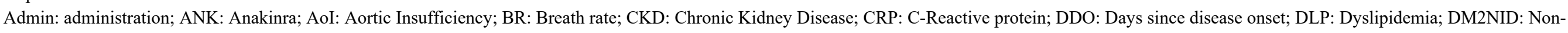
insulin dependent diabetes mellitus II; HBP: High Blood Pressure; IL-6; Interleukin 6; Lympho: Total lymphocytes; PAFI: PaO2/FiO2; TCZ: Tocilizumab; U: Unknown. 
Supplementary Table S1. Treatment schedules and clinical outcomes

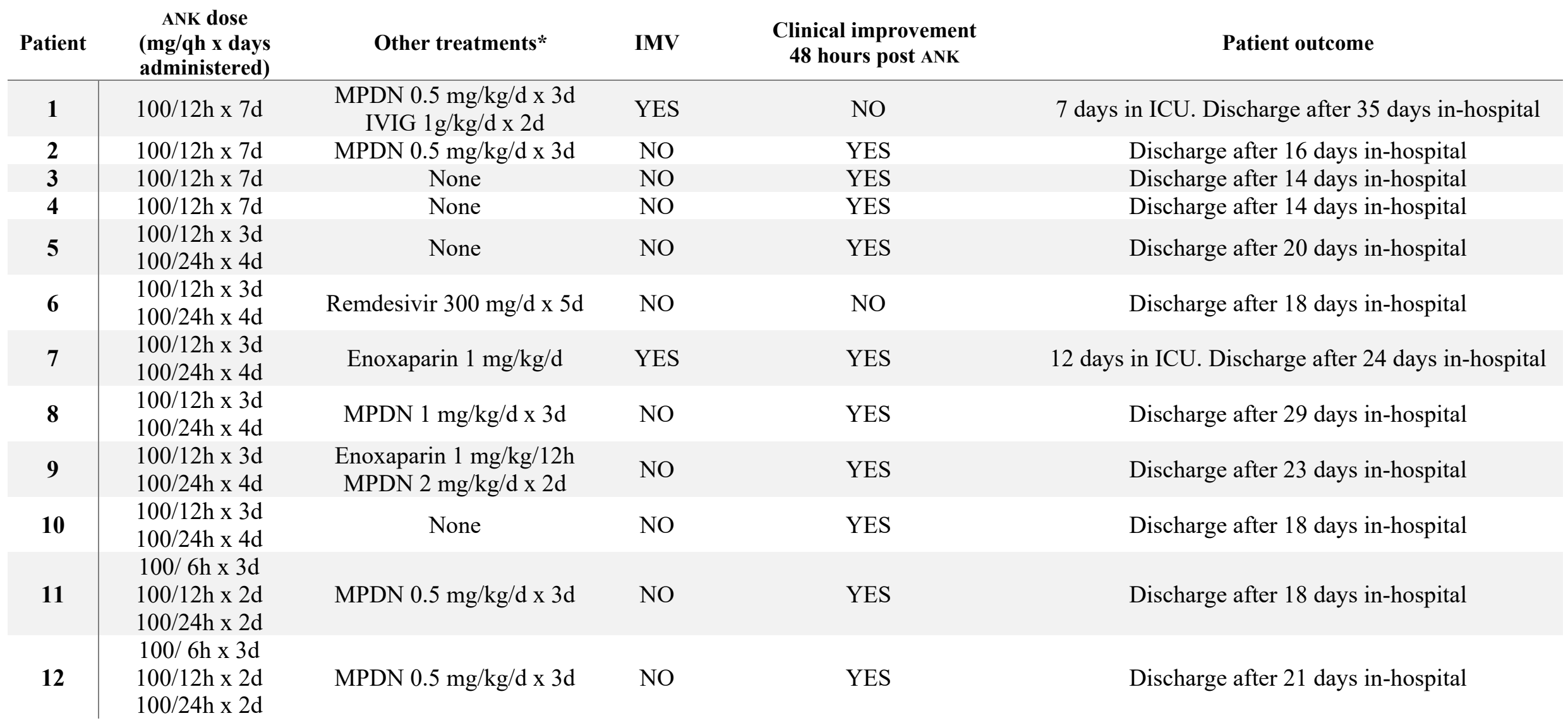

*All patients were treated with tocilizumab after quadruple therapy with Lopinavir/ritonavir + Hydroxychloroquine + azithromycin + enoxaparin $0.4 \mathrm{mg} / \mathrm{kg} / \mathrm{day}$. All treatments were administered previously to Anakinra; ICU: Intensive Care Unit; IMV: Invasive Mechanical Ventilation; IVIG: Intravenous Immunoglobulin; MPDN: methylprednisolone. 
A

adm $=\mathrm{TCZ} 24 \mathrm{~h}=\mathrm{ANK}$ Oh $=\mathrm{ANK} 48 \mathrm{~h}=\mathrm{ANK} 7 \mathrm{~d}=\mathrm{Disch}$

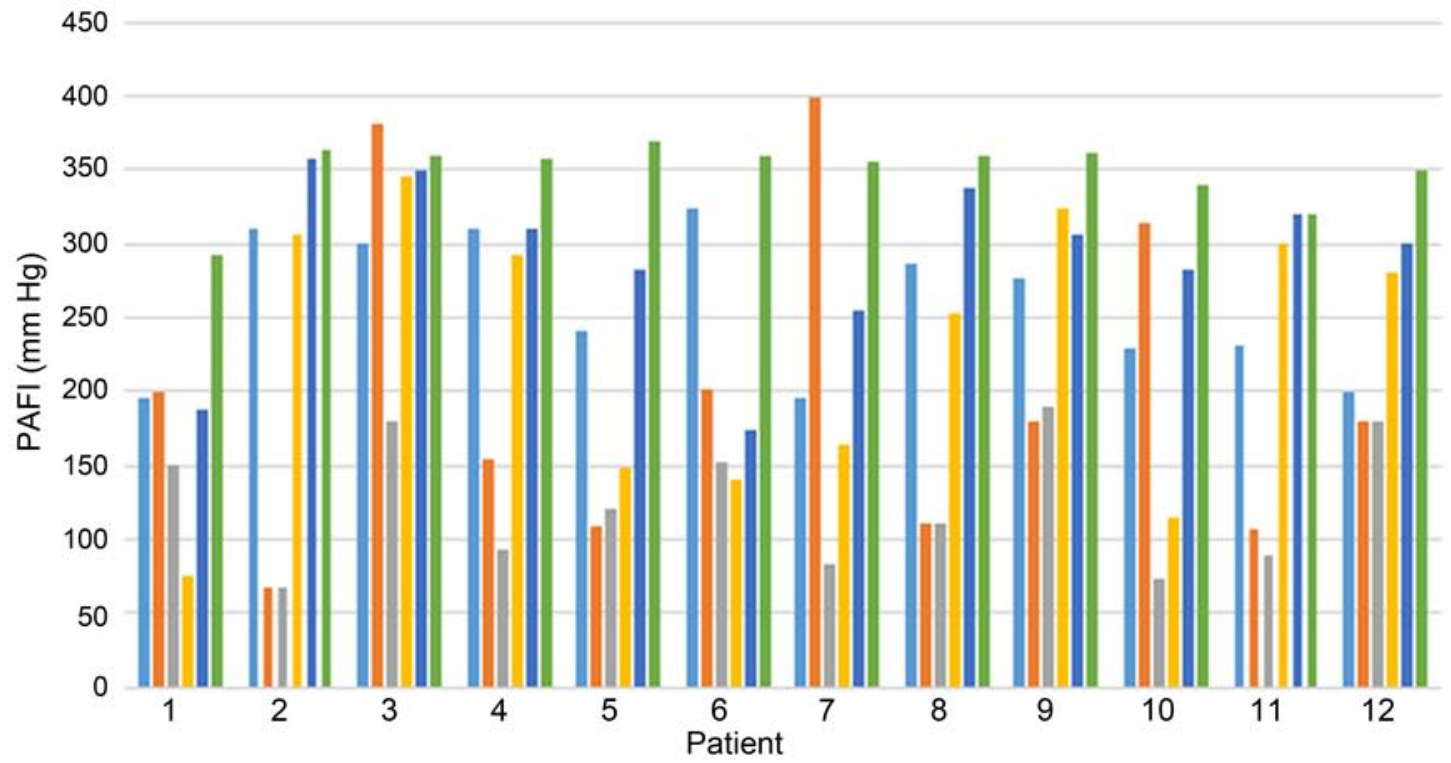

B

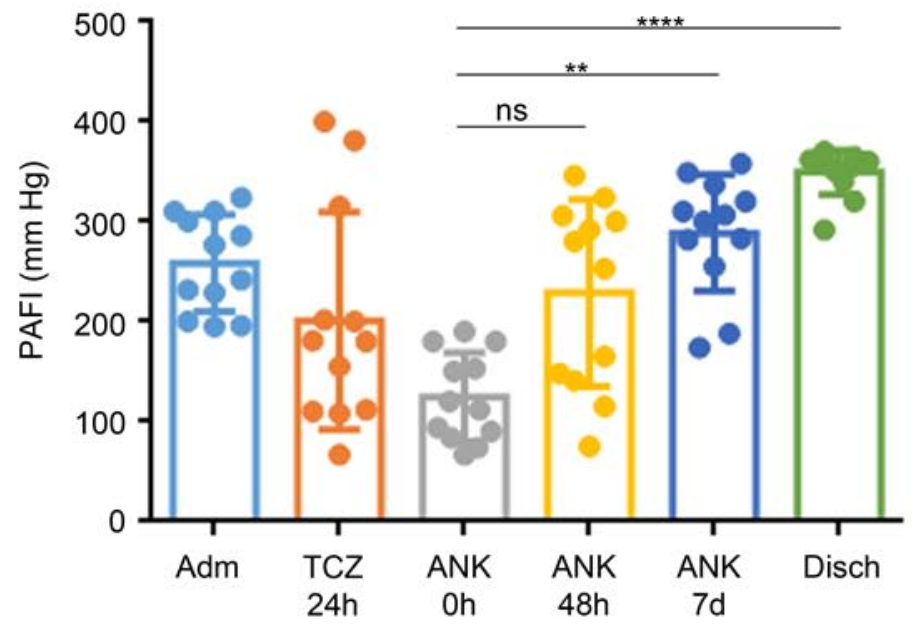




\section{Figures}

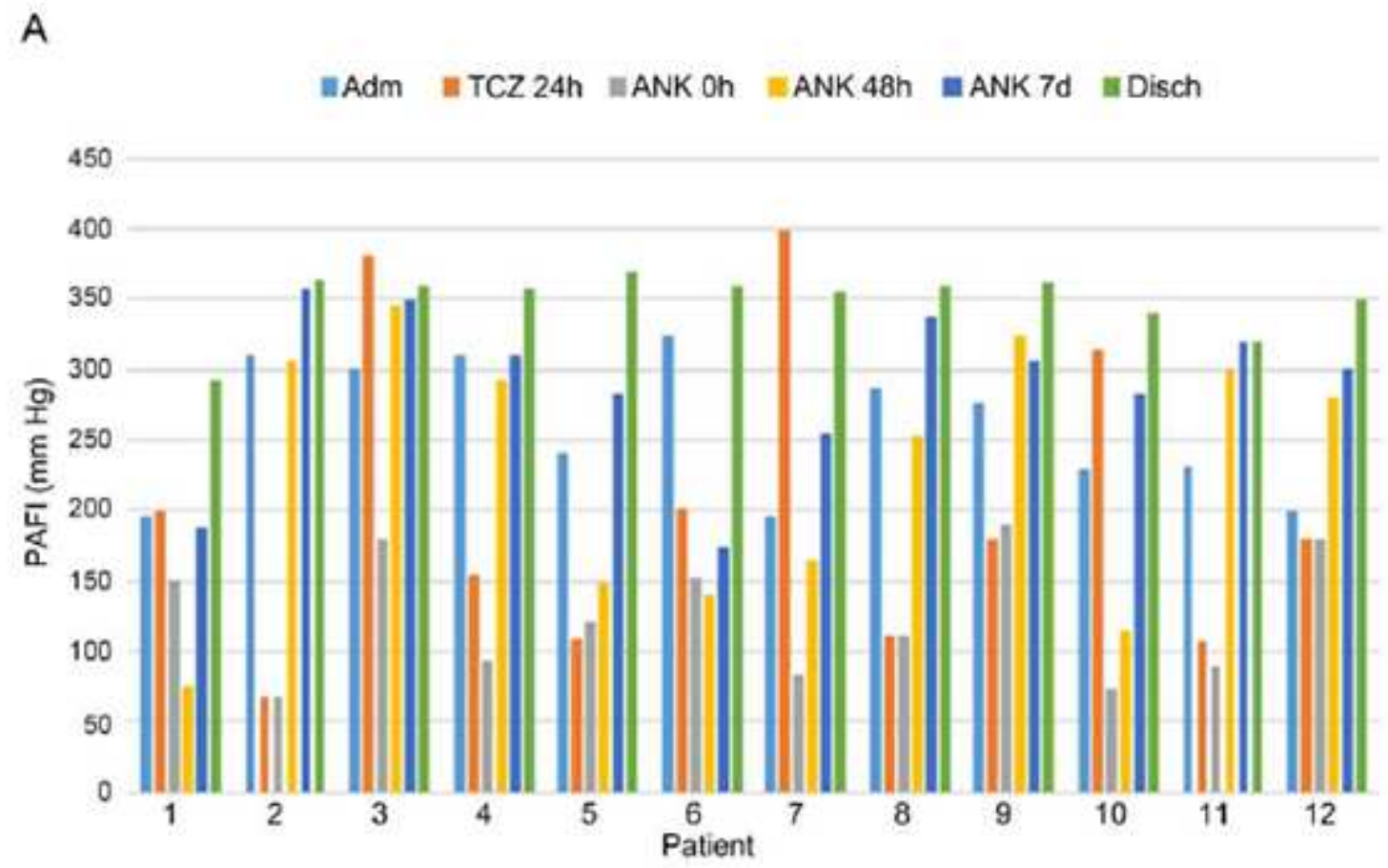

B

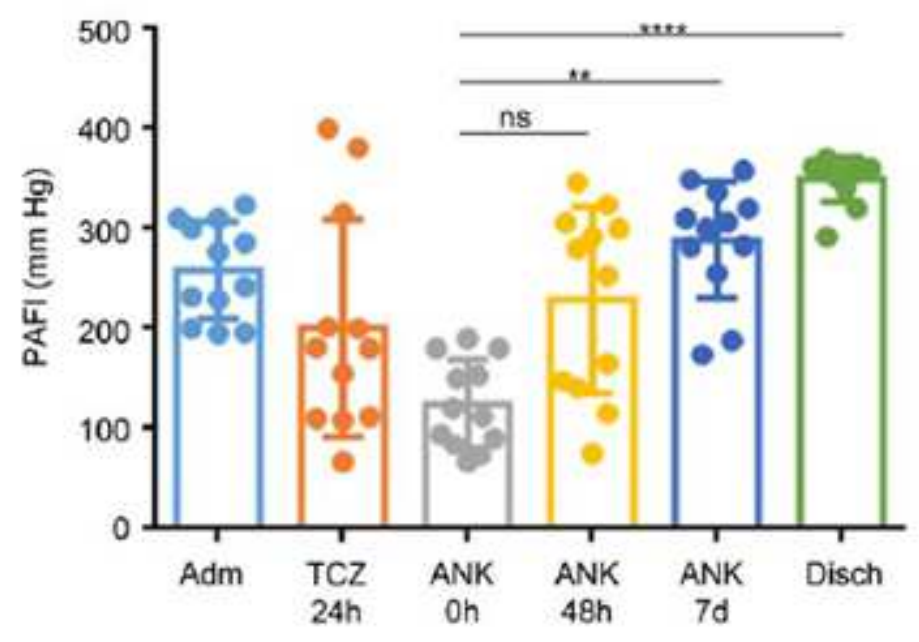

Figure 1

PAFI evolution during patient hospitalization. (A) Patients from 1 to 12 are showed individually and each bar represent PAFI assessment at a specific time during treatment. (B) Comparisons of PAFI among treatments over time. Each dot represents a patient. Non-parametric one-way ANOVA with Dunn's multiple comparisons (ns, non-significant; $\left.{ }^{\star \star} p<0.01 ; \star \star \star \star ~ p<0.0001\right)$. Legend: Adm, admission; TCZ 24h, 24 hours 
after tocilizumab administration; ANK Oh, at the moment of anakinra administration; ANK 48h, 48 hours after anakinra administration; ANK 7d, 7 days after anakinra administration; Disch, discharge. 